\title{
Bereitschaftspotential preceding eyelid blinks in Parkinson's disease
}

\author{
Potencial de Bereitschafts precedendo o piscamento ocular na doença de Parkinson \\ Isabella Araújo Mota', Maria das Graças Coriolano², Otávio Gomes Lins ${ }^{3}$
}

\begin{abstract}
The Bereitschaftspotential (BP) is a negative wave observed in EEG retrograde averaging, preceding a motor act. The objective was to study the BP preceding voluntary eyelid blinks in Parkinson's disease (PD) patients during off and on phases of levodopa. Methods: Ten PD patients in stages 1 and 2 of the Hoehn \& Yahr classification were compared to 18 healthy controls. Artifact-free EEG segments of two seconds preceding the onset of the blink potential were averaged and analyzed, and the statistical significance of the measured amplitudes were evaluated by analysis of variance models. Results: The presence of a BP in the PD patients was demonstrated. The mean amplitudes at $0 \mathrm{~ms}$ were respectively $0.6 \mu \mathrm{V}$ and $3.3 \mu \mathrm{V}$ for the BP patients and the normal controls, respectively. Conclusions: The BP amplitudes were significantly smaller in PD patients than normal participants. The amplitudes of the BP were not modified by levodopa.
\end{abstract}

Keywords: contingent negative variation; Parkinson disease; levodopa

\section{RESUMO}

O Potencial de Bereitschafts (PB) é uma onda negativa observada retrogradamente no EEG precedendo um ato motor. Objetivo: Estudar o PB precedendo o piscamento palpebral voluntário em pacientes com doença de Parkinson (DP) durante as fases off e on da levodopa. Foram comparados dez pacientes com DP nos estágios 1 e 2 de Hoehn \& Yahr com 18 controles saudáveis. Os segmentos de EEG livres de artefatos 2 segundos antes do início do potencial foram calculados e analisados e a significância estatística das amplitudes foi medida por modelos de análise de variância. Resultados: A presença de PB nos pacientes com DP foi demonstrada. As amplitudes médias a 0 ms foram respectivamente $0,6 \mu \mathrm{V}$ e 3,3 $\mu \mathrm{V}$ para os pacientes com DP e controles respectivamente. Conclusões: As amplitudes do PB foram significativamente menores nos pacientes com DP do que controles. As amplitudes do PB não foram modificadas pela levodopa.

Palavras-chave: variação contigente negativa; doença de Parkinson; levodopa

The increasing prevalence and incidence of Parkinson's disease (PD), along with the increase in the population's life expectancy, has made it the second most frequent neurodegenerative disorder. This has a significant socio-economic impact on the quality of life of PD patients and caregivers due to progressive physical dependence in activities of daily living, in addition to subsequent cognitive impairment.

Hypomimia, or masked facies, in PD is characterized by reduced automatic and voluntary facial muscle expressiveness from the early stages, progressing with advancing disease ${ }^{1}$ and generating social implications due to the expressionless, apathetic, depressed and introspective appearance ${ }^{2}$. Among the hypomimia findings, there is a decrease of the frequency of eyelid blink by different pathways related to the planning and execution of this motor act. This signal is one component of the extensive bradykinesia presentation.

Bradykinesia results from neuronal damage to pathways related to motor planning ${ }^{3}$. Voids in the dopaminergic and nondopaminergic circuits have been involved in this pathophysiology, generating an imbalance between inhibition and excitation, deficits and compensation ${ }^{4.5,6}$. Changes in the dopaminergic pathways explain, at least in part, disturbances in the kinematics of spontaneous eyelid blink ${ }^{7,8,9}$, and the voluntary one ${ }^{10}$ and in the blink reflex habituation of $\mathrm{PD}^{11}$.

Pharmacological treatment with dopaminergic medications, considered the gold standard ${ }^{12,13}$, results in partial problem-solving of bradykinesia as it improves the speed of movement ${ }^{7,8,10}$, but not its rhythm and amplitude ${ }^{14}$, although the damage regarding the amplitude is very evident ${ }^{1}$.

\footnotetext{
${ }^{1}$ Hospital Universitário Lauro Wanderley, Ambulatório de Neurologia, João Pessoa PB, Brasil;

${ }^{2}$ Universidade Federal de Pernambuco, Departamento de Anatomia, Recife PE, Brasil;

${ }^{3}$ Universidade Federal de Pernambuco, Departamento de Neuropsiquiatria, Recife PE, Brasil.

Correspondence: Isabella Araújo Mota Fernandes; BR 230, Km 10, Condomínio Villas do Atlântico, casa 3B; 58310-000 Cabedelo PB, Brasil;

E-mail: isabella_mota@yahoo.com.br

Conflict of interest: There is no conflict of interest to declare.

Received 10 February 2017; Accepted 04 May 2017.
} 
Bereitschaftspotential (BP), or readiness potential, described by Kornhuber and Deecke in 1964 corresponds to the negative gradient starting one-and-a-half to two seconds before the motor potential, seen in electroencephalogram (EEG) retrograde averaging. This potential is divided into an early component related to planning and a late potential related to motor execution ${ }^{15,16,17}$. This study aimed to evaluate the ocular blink in patients with PD in the off (without levodopa) and on phases (with levodopa) by measuring the BP.

\section{METHODS}

\section{Subjects}

The study was approved by the University Human Research Ethics Committee (statement 90208). All participants signed an informed consent form.

Ten PD patients (nine males) aged 43 to 78 years were randomly recruited in the Parkinsonian Patient Care Service (Pro-Parkinson) at the Clinic Hospital of the Federal University of Pernambuco, Brazil. All patients were diagnosed by a neurologist trained in movement disorders. Eighteen normal individuals (eight males) aged 17 to 60 years served as a comparison group. The analysis of this normal data was recently accepted for publication ${ }^{18}$.

\section{Procedures}

The participants sat comfortably on a chair and were instructed to relax, restrain moving the muscles of the neck, head or face and fix their gaze on a spot placed two meters away at eye level, blinking as naturally as possible, once every ten seconds. There were no auditory or visual clues for the time of blinking and the rhythm was rehearsed before starting the recordings.

The PD patients who met the inclusion criteria were invited to return the next morning. The patients were instructed not to take their morning anti-Parkinson's medication, before coming to the laboratory. They were also advised to avoid the intake of protein foods.

The PD patients were initially recorded at least 12 hours after the last anti-Parkinson's medication (off phase). Then levodopa/benserazide 100/25 mg was offered and, after 40 minutes, a second recording section (on phase) was made. The normal controls were recorded only once.

The EEG was recorded from 11 EEG electrodes placed in positions $\mathrm{F} 3, \mathrm{FZ}, \mathrm{F} 4, \mathrm{C} 3, \mathrm{Cz}, \mathrm{C} 4, \mathrm{P} 3, \mathrm{Pz}, \mathrm{P} 4, \mathrm{O} 1, \mathrm{O} 2$ of the international 10-20 system of electrode placement, referenced to two electrodes placed on the mastoids and linked together. The vertical electrooculogram was recorded from two electrodes placed one centimeter above and below the right eye. The ground electrode was placed on the skin over the right clavicle.

The recordings were made using a Neuron-Spectrum NET polygraph (Neurosoft). The bandpass of the filters were $0.1 \mathrm{~Hz}$ to $35 \mathrm{~Hz}$. Inter-electrode impedances $(10 \mathrm{~Hz})$ were kept below $3 \mathrm{k} \Omega$.

\section{Data analysis}

Blinks were visually identified as large positive deflections on the vertical electrooculogram channel and the beginning of the blink potential was marked. The two-second EEG segments preceding the mark were back-averaged together. Blinks that presented artifacts during or close to this period were eliminated from the analysis.

The averages were saved in text files and analyzed in a specific program written in Matlab software. Initially, the waves obtained by the general averaging of each group of participants were observed. The measurement points were established at $-1800 \mathrm{~ms}$ (at the beginning of the BP), $-500 \mathrm{~ms}$ (at the start of the late component of the BP) and 0ms (at the onset of the blink potential). To compensate for background noise, the amplitudes were averaged in a $100 \mathrm{~ms}$ segment centered on the latency to be measured.

Statistical analysis of the BP amplitudes was performed on the C3, C4 and Cz electrodes, using the STATISTICA version 10 statistical package (StatSoft). The statistical analysis was performed using analysis of variance (ANOVA) models. A three-way repeated measures ANOVA model, condition (off and on), time (-1800 ms, $-500 \mathrm{~ms}, 0 \mathrm{~s})$ and electrodes (C3, Cz, C4) was used to compare the PD group during the off phase and the on phase. A mixed-model ANOVA, group (PD and controls) and two repeated-measures, time (-1800 ms, -500 ms and $0 \mathrm{~ms}$ ) and electrode (C3, $\mathrm{Cz}$ and $\mathrm{C} 4)$, was used to compare the PD patients with the normal controls. The GeisserGreenhouse correction was applied for violation of sphericity. The Newman-Keuls test was used for post hoc analysis, when necessary. The critical p-value was 0.05 .

\section{RESULTS}

Table 1 lists some demographic and clinical characteristics of the studied PD patients.

Table 1. Some characteristics of the studied Parkinson's disease patients.

\begin{tabular}{lcccccccc} 
Initials & Sex & Age & TD & H\&Y & $\begin{array}{c}\text { UPDRS } \\
\text { II }\end{array}$ & $\begin{array}{c}\text { UPDRS } \\
\text { III }\end{array}$ & $\begin{array}{c}\text { UPDRS } \\
\text { T }\end{array}$ & MMSE \\
\hline AC & M & 43 & 8 & 3 & 9 & 14 & 23 & 29 \\
EL & M & 44 & 3 & 1 & 10 & 29 & 39 & 25 \\
DA & M & 48 & 6 & 1 & 10 & 15 & 25 & 30 \\
\hline SF & F & 52 & 2 & 1 & 10 & 24 & 34 & 26 \\
JF & $M$ & 58 & 4 & 1 & 12 & 30 & 42 & 27 \\
CE & $M$ & 53 & 5 & 2 & 19 & 90 & 109 & 30 \\
MA & $M$ & 61 & 3 & 1 & 11 & 29 & 40 & 30 \\
AJ & $M$ & 61 & 5 & 1 & 5 & 20 & 25 & 30 \\
EV & $M$ & 68 & 1 & 2 & 8 & 35 & 43 & 24 \\
JQ & $M$ & 78 & 4 & 1 & 5 & 7 & 12 & 30
\end{tabular}

M: male; F: female; TD: time of disease; HY: Hoehn and Yahr scale; UPDRS: unified Parkinson's disease rating scale; MMSE: mini-mental state examination. Age and TD in years. 
A total of 230 blinks during the off phase and 250 blinks during the on phase were averaged from the 10 PD patients, giving a mean of 23 blinks per patient during the off phase and 25 blinks per patient during the on phase.

Figure 1 shows the grand average of the EEG recorded at all electrodes from the PD patients in the off(dashed line) and on (solid line) phases.

In both conditions, a negative potential of increasing amplitude was observed starting around -1,500 ms before the blink onset. This potential had a broad scalp distribution, but was most evident at the central regions. Around $-500 \mathrm{~ms}$ before the blink potential, a change in the wave configuration was observed. No obvious differences were seen between the potentials obtained during the off phase and the on phase.

Figure 2 shows the analysis of the amplitudes of the potentials at $\mathrm{C} 3, \mathrm{Cz}$ and $\mathrm{C} 4$ electrodes measured $-1800 \mathrm{~ms}$, $-500 \mathrm{~ms}$ and $0 \mathrm{~ms}$ before the onset of the blink potential. The waveforms and measurement times are shown at the top of the figure. Amplitudes were averaged in a segment of $100 \mathrm{~ms}$ centered on the latency to be measured (vertical gray shadows). The means and standard deviations of the amplitudes at each electrode, condition and time-point are illustrated at the bottom of the figure. Table 2 shows the ANOVA of the data.

The ANOVA showed a significant effect for time. No interactions were significant. The post hoc analysis (NewmanKeuls) showed that the amplitudes at $-500 \mathrm{~ms}$ (onset of the late component) and $0 \mathrm{~ms}$ (end of the $\mathrm{BP}$ ) were both significantly larger than the amplitude at -1800 ms (just before the onset of the early BP component). The amplitudes at -500 and $0 \mathrm{~ms}$ were not different. This is consistent with the presence of a BP preceding the voluntary blink of PD patients, during both off and on phases. No significant differences between the amplitudes during the off phase and the on phase were observed.

A total of 900 blinks were averaged from the 18 normal controls, giving a mean of 50 blinks per individual. As there were no significant differences between the measured amplitudes of the BP during off and on phases, all 580 blinks from the $10 \mathrm{PD}$ patients were averaged, giving a mean of 58 blinks per participant.

Figure 3 shows the analysis of the amplitudes of the potentials at $\mathrm{C} 3, \mathrm{Cz}$ and $\mathrm{C} 4$ measured $-1800,-500$ and $0 \mathrm{~ms}$ before the onset of the blink potentials from the PD patients (solid line) and the normal controls (dashed line). The waveforms and measurement times are shown at the top of the figure. The means and standard deviations of the amplitudes at each electrode, condition and time-point are illustrated at the bottom of the figure. Different scales were used for the PD patients (right side) and for the control group (left side). Table 3 shows the ANOVA of the data.

The ANOVA showed a significant interaction between the time and the group. The post hoc analysis showed that the amplitudes at -500 ms and 0ms were both significantly larger in the control group than in the PD group. At $-1800 \mathrm{~ms}$ the amplitudes were not different between groups. Therefore, the amplitude of the BP of PD patients is significantly smaller than the $\mathrm{BP}$ of normal controls at all analyzed electrode positions.
F3

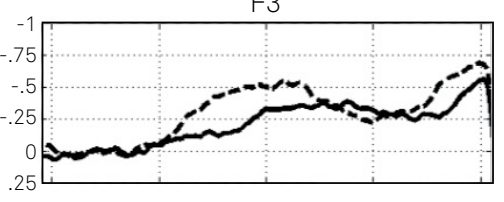

C3

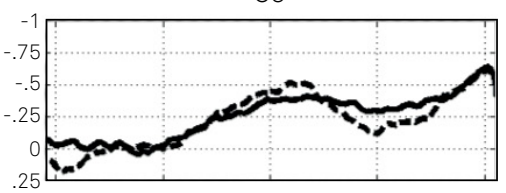

P3

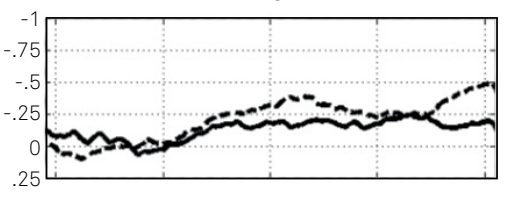

01

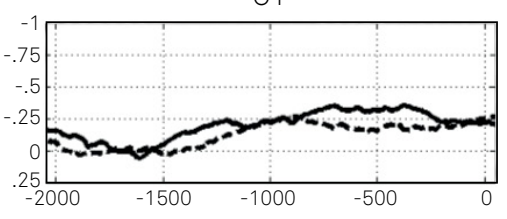

Fz

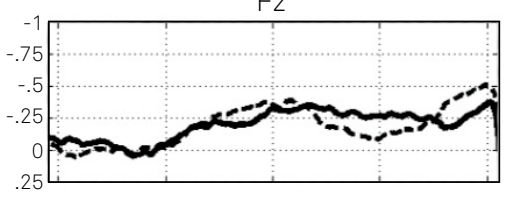

$\mathrm{Cz}$

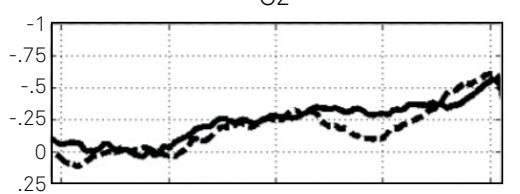

$\mathrm{Pz}$

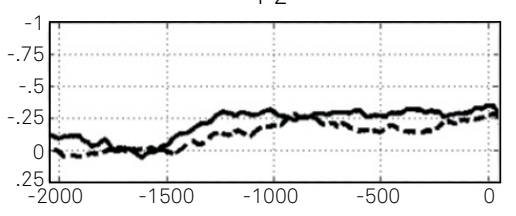

On

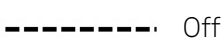

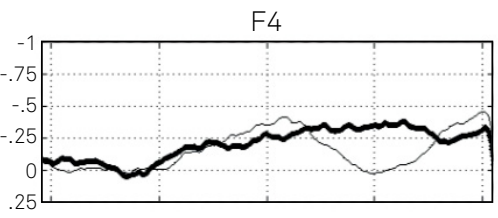

C4

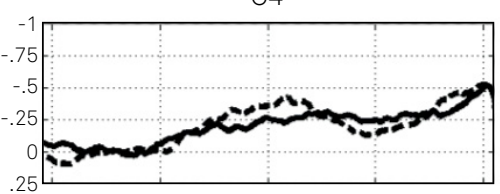

P4

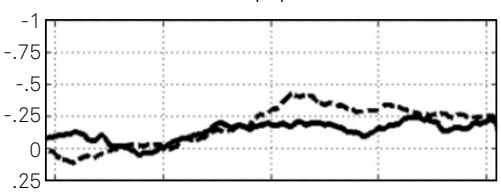

02

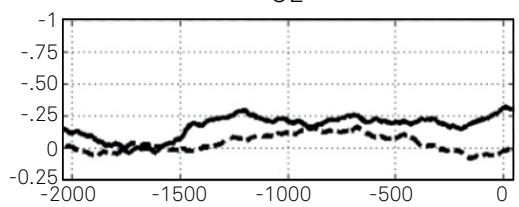

Figure 1. Grand average of the bereitschaftspotential of the Parkinson's disease patients during the off phase (dashed line) and on phase (solid line) of medication at all electrode positions. 
Table 2. Factorial repeated-measurement analysis of variance of the amplitudes of the bereitschaftspotential of the Parkinson's disease patients, with three repeated measurements: condition (off and on medication), time (-1800, -500 and $0 \mathrm{~ms}$, relative to the onset of the blink potential) and electrode (C3, Cz and C4).

\begin{tabular}{|c|c|c|c|c|c|}
\hline Variable & SS & $d f$ & MS & $\mathrm{F}$ & $p$ \\
\hline Intercept & 11.706 & 1 & 11.706 & 12.145 & 0.007 \\
\hline Error & 8.675 & 9 & 0.964 & & \\
\hline Condition & 0.212 & 1 & 0.212 & 0.284 & 0.607 \\
\hline Error & 6.716 & 9 & 0.746 & & \\
\hline Time & 9.552 & 2 & 4.776 & 7.072 & $0.005^{\star}$ \\
\hline Error & 12.157 & 18 & 0.676 & & \\
\hline Electrode & 0.063 & 2 & 0.032 & 0.099 & 0.906 \\
\hline Error & 5.730 & 18 & 0.318 & & \\
\hline Condition $\times$ time & 0.260 & 2 & 0.130 & 0.275 & 0.762 \\
\hline Error & 8.494 & 18 & 0.472 & & \\
\hline Condition $\times$ electrode & 0.021 & 2 & 0.010 & 0.207 & 0.815 \\
\hline Error & 0.8900 & 18 & 0.049 & & \\
\hline Time $\times$ electrode & 0.064 & 4 & 0.016 & 0.176 & 0.950 \\
\hline Error & 3.293 & 36 & 0.092 & & \\
\hline Condition $\times$ time $\times$ electrode & 0.018 & 4 & 0.005 & 0.063 & 0.992 \\
\hline Error & 2.534 & 36 & 0.070 & & \\
\hline \multicolumn{6}{|c|}{ Newman-Keuls test of the main effect TIME } \\
\hline$-1800 \mathrm{~ms} \times 0 \mathrm{~ms}$ & & & & & $0.005^{\star}$ \\
\hline$-1800 \mathrm{~ms} \times-500 \mathrm{~ms}$ & & & & & $0.024^{\star}$ \\
\hline$-500 \mathrm{~ms} \times 0 \mathrm{~ms}$ & & & & & 0.233 \\
\hline
\end{tabular}

SS: Sum of squares; Df: Degrees of freedon; MS: mean squares; F: ANOVA Statistic * $P<0.05$

C3

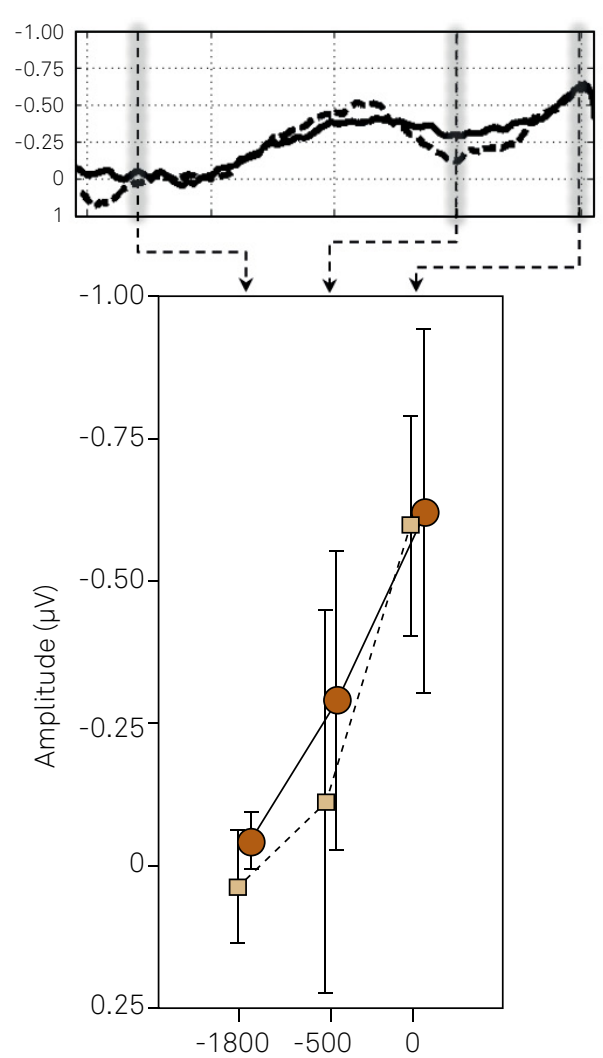

$\mathrm{Cz}$
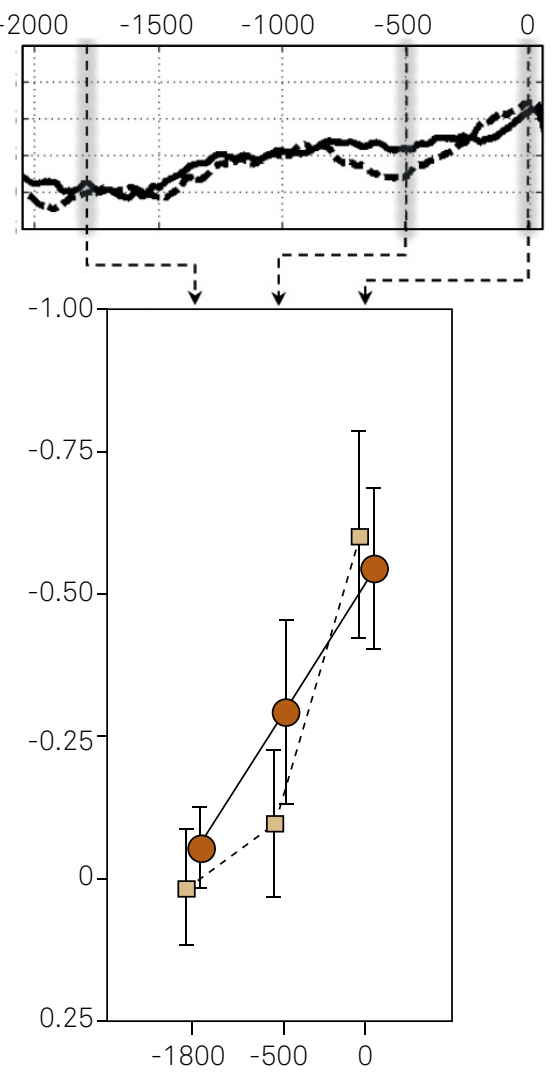

C4

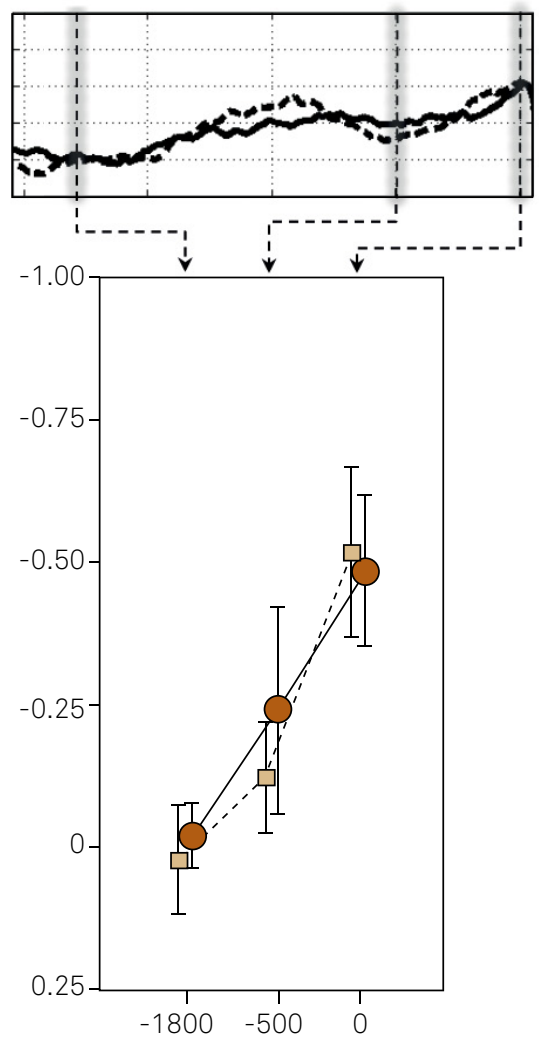

Time (ms)

Figure 2. Analysis of the amplitudes of the bereitschaftspotential of the Parkinson's disease patients at C3, Cz and C4 electrodes measured $-1800,-500$ and $0 \mathrm{~ms}$ before the onset of the blink potentials. The waveforms and measurement times are shown on the top of the figure. Amplitudes were averaged within a segment of $100 \mathrm{~ms}$ centered on the latency to be measured (vertical gray shadows). The means and standard deviations of the amplitudes at each electrode, condition and time-point are illustrated at the bottom of the figure. 

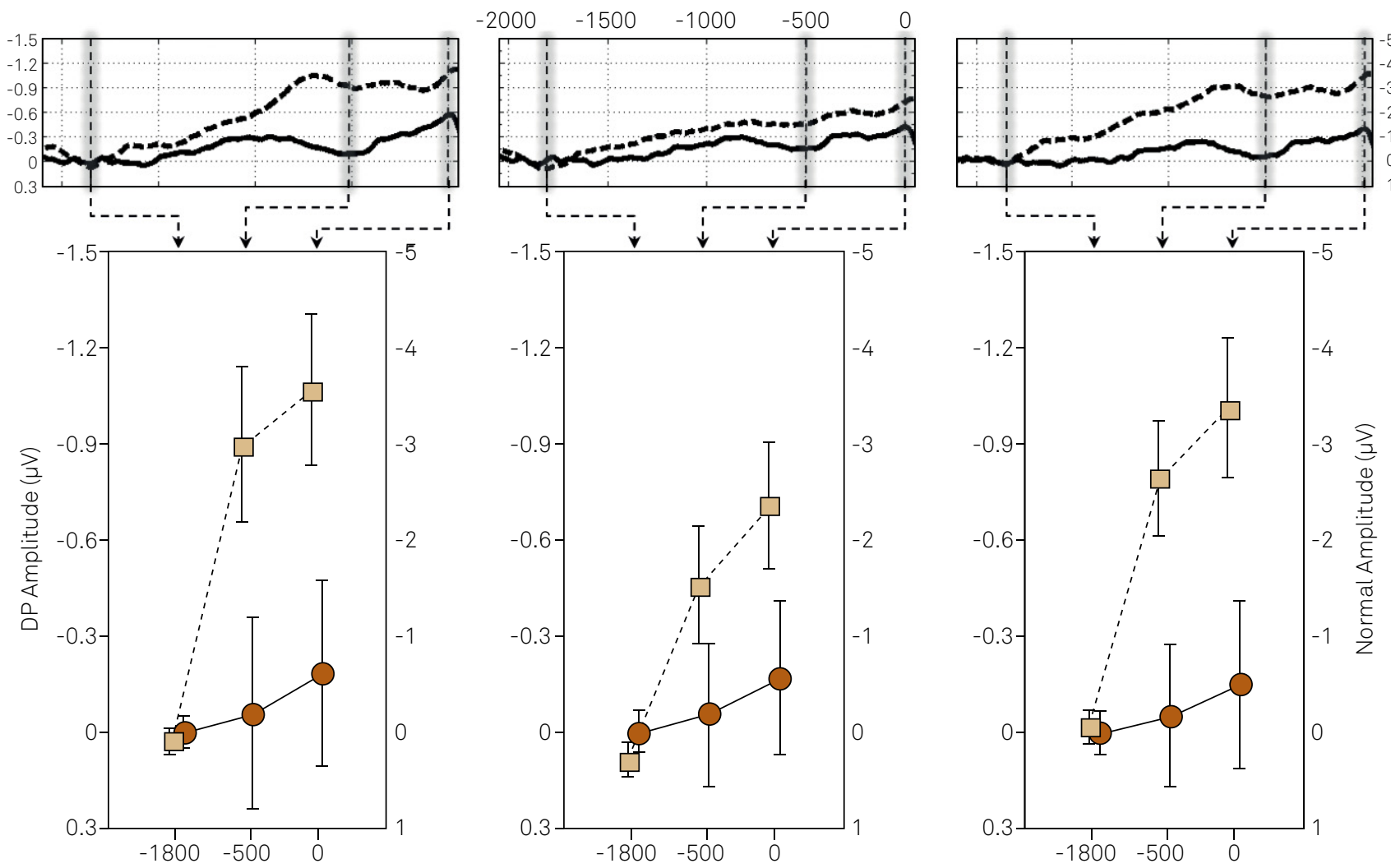

Time (ms)

Figure 3. Analysis of the amplitudes of the bereitschaftspotential of the Parkinson's disease patients (grand average of all recordings during the off phase and the on phase) and the normal controls at C3, Cz and C4 electrodes measured -1800, -500 and $0 \mathrm{~ms}$ before the onset of the blink potentials. The waveforms and measurement times are shown on the top of the figure. Amplitudes were averaged within a segment of $100 \mathrm{~ms}$ centered on the latency to be measured (vertical gray shadows). The means and standard deviations of the amplitudes at each electrode, condition and time-point are illustrated at the bottom of the figure. Different scales were used for the PD patients (right side) and the normal controls (left side).

Table 3. Factorial mixed-model analysis of variance of the amplitudes of the bereitschaftspotential of the Parkinson's disease patients and normal controls: Group (PD patients and normal controls) and two repeated measures: time (-1800, -500 e 0 ms, relative to the onset of the blink potential) and electrode (C3, Cz and C4).

\begin{tabular}{|c|c|c|c|c|c|}
\hline Variable & SS & Df & MS & $\mathrm{F}$ & p* \\
\hline Intercept & 227.770 & 1 & 227.770 & 10.379 & $0.004^{*}$ \\
\hline Group & 128.687 & 1 & 128.687 & 5.864 & $0.024^{*}$ \\
\hline Error & 504.716 & 23 & 21.944 & & \\
\hline Time & 134.349 & 2 & 67.175 & 7.847 & $0.001 *$ \\
\hline Time $\times$ group & 74.475 & 2 & 37.238 & 4.350 & $0.019 *$ \\
\hline Error & 393.785 & 46 & 8.561 & & \\
\hline Electrode & 9.394 & 2 & 4.697 & 2.296 & $0.112^{\star}$ \\
\hline Electrode $\times$ group & 9.731 & 2 & 4.866 & 2.379 & $0.104 *$ \\
\hline Error & 94.087 & 46 & 2.045 & & \\
\hline Time $\times$ electrode & 2.860 & 4 & 0.715 & 1.244 & $0.298 *$ \\
\hline Time $\times$ electrode $\times$ group & 2.665 & 4 & 0.666 & 1.159 & $0.334^{\star}$ \\
\hline Error & 52.878 & 92 & 0.5748 & & \\
\hline \multicolumn{6}{|c|}{ Newman-Keuls test of the interaction time $\times$ group } \\
\hline Parkinson $\times$ Control at $-1800 \mathrm{~ms}$ & & & & & 0.902 \\
\hline Parkinson $\times$ Control at $-500 \mathrm{~ms}$ & & & & & $0.033^{*}$ \\
\hline Parkinson $\times$ Control at $0 \mathrm{~ms}$ & & & & & $0.012^{*}$ \\
\hline
\end{tabular}

SS: Sum of squares; Df: Degrees of freedon; MS: mean squares; F: ANOVA Statistic* $P<0.05$ 


\section{DISCUSSION}

This study demonstrated that there is a BP preceding voluntary blinks in PD patients. This BP does not differ significantly during the off phase and the on phase of medication. To our knowledge, there have been no studies on BP preceding blinks in PD patients. In a previous recently-accepted study ${ }^{18}$, we reported the presence of a BP preceding voluntary (but not spontaneous blinks) in normal participants.

The BP of DP patients had a broad scalp distribution, most clearly identified at the central regions, similar to the $\mathrm{BP}$ of normal controls and to the $\mathrm{BP}$ preceding other movements in PD and normal controls ${ }^{19,20,21}$.

The amplitude of the BP of the PD patients was much smaller than the BP of the control group, even though the PD patients were at a relatively mild stage of the disease. At its largest negativity (just preceding the blink) the mean amplitudes of the BP of the PD patients and the normal controls were respectively $0.6 \mu \mathrm{V}$ and $3.3 \mu \mathrm{V}$. This suggests a significant dysfunction of the motor neural networks, even in patients with few symptoms. This finding is consistent with previous descriptions of reduced amplitude of BP preceding other movements in PD patients, even in the early stages ${ }^{12,22,23,24,25,26}$. It is also in accordance with the early clinical finding of paucity of facial expression and reduced blink rate in PD patients, suggesting that neural systems related to motor planning, especially those related to facial expression and blinks, are affected early in $\mathrm{PD}^{1}$.

Most PD patients were at stage 1 of the H\&Y scale and showed low scores on the motor and daily living activities of the Unified Parkinson's Disease Rating Scale. Although the disease has a progressive symptomatology, it is known that damage to neuronal pathways begins 8-17 years before the appearance of the first symptoms, with different progression characteristics depending on the compensatory mechanisms and the age of onset. Therefore, even patients who are diagnosed early may present with significant neural dysfunction.

Although most studies have reported smaller BP amplitudes in PD patients compared to normal controls, some studies have reported no differences ${ }^{21,24,26}$ or even larger amplitudes $^{27,28}$. The reasons for these discrepancies are not clear.

In our study, the dopaminergic drug did not significantly affect the BP. A larger amplitude during the on phase has been described in $\mathrm{BP}$ preceding the movement of the fingers ${ }^{22,23}$.
The absence of an influence by levodopa on the BP preceding the eye blink may result from an earlier, and more severe, dysfunction of the dopaminergic networks involved in the planning of eye blinks, than finger movements.

Although levodopa is considered the gold standard drug for PD therapy, it does not appear to act on all the mechanisms that cause bradykinesia ${ }^{14}$. Nondopaminergic pathways play a role in the clinical improvement of motor planning and BP amplitude in PD patients, as observed after unilateral posteroventral pallidotomy ${ }^{28}$ and after neurofeedback techniques ${ }^{25}$. These studies corroborate the presence and importance of nondopaminergic or dopaminergic pathways resistant to modulation mechanisms of the motor planning in $\mathrm{PD}^{6}$.

The amplitudes at $\mathrm{C} 3, \mathrm{Cz}$ and $\mathrm{C} 4$ were not significantly different in $\mathrm{PD}$ patients. In our previous study with normal controls $^{18}$, we found larger amplitudes at C3 and C4 in relation with $\mathrm{Cz}$. This was also observed by Yamamoto ${ }^{29}$, but not Shimizu and Okiyama ${ }^{20}$, in their study with saccadic movements. A lateral component of the BP source complex, perhaps the face motor cortex, is less active in PD patients than in normal subjects. A source analysis study may shed some light on this issue.

The main objective of this study was to determine if a BP preceding voluntary blinks could be demonstrated in PD patients. We believe this was accomplished. The potentials we obtained had very low amplitudes in comparison with the potentials obtained from normal participants. Although the normal participants we used were not perfectly age-matched with the PD patients, we believe the differences in amplitudes are obvious. Furthermore, it has been shown that there is no significant change in BP amplitudes with increasing age, within certain limits ${ }^{30}$.

In conclusion, this is the first study demonstrating a BP preceding eyelid blinks in PD patients. The BP of the PD patients had much smaller amplitudes than the BP of normal subjects, even though the PD patients were in the early stages of the disease. These potentials could be used in the future as early diagnostic and evolutionary markers of Parkinson's disease. Further investigations should be conducted. Currently considered the gold standard drug in Parkinson's disease, levodopa did not obviously modify the BP preceding blinks, suggesting that the resistant nondopaminergic or dopaminergic accessory pathways related to motor planning should be investigated in search of more effective medications.

\section{References}

1. Korosec M, Zidar I, Reits D, Evinger C, Vanderwerf F. Eyelid movements during blinking in patients with Parkinson's disease. Mov Disord. 2006;21(8):1248-51. https://doi.org/10.1002/mds.20930

Tickle-Degnen L, Zebrowitz LA, Ma HI. Culture, gender and health care stigma: practitioners' response to facial masking experienced by people with Parkinson's disease. Soc Sci Med. 2011;73:95-102. https://doi.org/10.1016/j.socscimed.2011.05.008
3. Berardelli A, Rothwell JC, Thompson PD, Hallett M. Pathophysiology of bradykinesia in Parkinson's disease. Review Article. Brain. 2001;124(11): 2131-46. https://doi.org/10.1093/brain/124.11.2131

4. Almeida QJ, Brown MJN. Is DOPA-responsive hypokinesia responsible for bimanual coordination deficits in Parkinson's disease? Front Neurol. 2013;4:89. https://doi.org/10.3389/fneur.2013.00089 
5. Yu R, Liu B, Wang L, Chen J, Liu X. Enhanced functional connectivity between putamen and supplementary motor area in Parkinson's disease patients. PLoS One. 2013;8:59717. https://doi.org/10.1371/journal.pone.0059717

6. Gröger A, Kolb R, Schäfer R, Klose U. Dopamine reduction in the substantia nigra of Parkinson's disease patients confirmed by in vivo magnetic resonance spectroscopic imaging. PLoS One. 2014;9(1):84081. https://doi.org/10.1371/journal.pone.0084081

7. Deuschl G, Goddemeier C. Spontaneous and reflex activity of facial muscles in dystonia, Parkinson's disease, and in normal subjects. J Neurol Neurosurg Psychiatry. 1998;64(3):320-4. https://doi.org/10.1136/jnnp.64.3.320

8. Taylor JR, Elsworth JD, Lawrence MS, Sladek JR Jr, Roth RH, Redmond DE Jr. Spontaneous blink rates correlate with dopamine levels in the caudate nucleus of MPTP-treated monkeys. Exp Neurol. 1999;158(1):214-20. https://doi.org/10.1006/exnr.1999.7093

9. Colzato LS, Wildenberg, WPM, Hommel, B. Reduced spontaneous eye blink rates in recreational cocaine users: evidence for dopaminergic hypoactivity. PLoS One. 2008;3(10):3461. https://doi.org/10.1371/journal.pone.0003461

10. Agostino R, Bologna M, Dinapoli L, Gregori B, Fabbrini G, Accornero $\mathrm{N}$ et al. Voluntary, spontaneous, and reflex blinking in parkinson's disease. Mov Disord. 2008;23(5):669-75. https://doi.org/10.1002/mds.21887

11. Penders CA, Delwaide PJ. Blink reflex studies in patients with Parkinsonism before and during therapy. J Neurol Neurosurg Psychiatry. 1971;34(6):674-8. https://doi.org/10.1136/jnnp.34.6.674

12. Tolosa E, Katzenschlager R. Pharmacological management of Parkinson's disease. In: Jankovic J, Tolosa E. Parkinson's disease and movement disorders. Philadelphia: Lippincott Williams and Wilkins; 2006. p. 113-6.

13. Porras G, De Deurwaerdere P, Li Q, Marti M, Morgenstern R, Sohr R et al. L-dopa-induced dyskinesia: beyond an excessive dopamine tone in the striatum. Sci Rep. 2014;4(1):3730. https://doi.org/10.1038/srep03730

14. Espay AJ, Giuffrida JP, Chen R, Payne M, Mazzella F, Dunn E et al. Differential response of speed, amplitude, and rhythm to dopaminergic medications in Parkinson's disease. Mov Disord. 2011;26(14):2504-8. https://doi.org/10.1002/mds.23893

15. Caviness JN, Evidente VG, Joshi N. An investigation on the reproducibility of the Bereitschaftspotential. Neurology. 1998;50:A224-5.

16. Shibasaki $\mathrm{H}$, Hallet M. What is the Bereitschaftspotential? Clin Neurophysiol. 2006;117(11):2341-56. https://doi.org/10.1016/j.clinph.2006.04.025

17. Colebatch JG. Bereitschaftspotential and movement-related potentials: origin, significance, and application in disorders of human movement. Mov Disord. 2007;22(5):601-60. https://doi.org/10.1002/mds.21323

18. Mota IA, Lins OG. Bereitschaftspotential preceding spontaneous and voluntary eyelid blinks in normal individuals. Clin Neurophysiol. 2017;128(1):100-5. https://doi.org/10.1016/j.clinph.2016.10.010
19. Shimizu N, Okiyama R. Bereitschaftspotential preceding voluntary saccades is abnormal in patients with Parkinson's disease. Adv Neurol. 1993;60:398-402

20. Jahanshahi M, Jenkins IH, Brown RG, Marsden CD, Passingham RE, Brooks DJ. Self-initiated versus externally triggered movements. I. An investigation using measurement of regional cerebral blood flow with PET and movement-related potentials in normal and Parkinson's disease subjects. Brain. 1995;118(4):913-33. https://doi.org/10.1093/brain/118.4.913

21. Praamstra P, Cools AR, Stegeman DF, Horstink MW. Movement-related potential measures of different modes of movement selection in Parkinson's disease. J Neurol Sci. 1996;140(1-2):67-74. https://doi.org/10.1016/0022-510X(96)00076-7

22. Dick JP, Rothwell JC, Day BL, Cantello R, Buruma O, Gioux M et al. The Bereitschaftspotential is abnormal in Parkinson's disease. Brain. 1989;112(1):233-44. https://doi.org/10.1093/brain/112.1.233

23. Cunnington R, lansek R, Johnson KA, Bradshaw JL. Movement-related potentials in Parkinson's disease. Motor imagery and movement preparation. Brain. 1997;120(8):1339-53. https://doi.org/10.1093/brain/120.8.1339

24. Filipović SR, Sternić N, Svetel M, Dragasević N, Lecic D, Kostić VS. Bereitschaftspotential in depressed and non-depressed patients with Parkinson's disease. Mov Disord. 2001;16(2):294-300. https://doi.org/10.1002/mds.1059

25. Fumuro T, Matsuhashi M, Mitsueda T, Inouchi M, Hitomi T, Nakagawa T et al. Bereitschaftspotential augmentation by neuro-feedback training in Parkinson's disease. Clin Neurophysiol. 2013;124(7):1398-405. https://doi.org/10.1016/j.clinph.2013.01.026

26. Touge T, Werhahn KJ, Rothwell JC, Marsden CD. Movement-related cortical potentials preceding repetitive and random-choice hand movements in Parkinson's disease. Ann Neurol. 1995;37(6):791-9. https://doi.org/10.1002/ana.410370613

27. Fattapposta F, Pierelli F, My F, Mostarda M, Del Monte S, Parisi L et al. L-dopa effects on preprogramming and control activity in a skilled motor act in Parkinson's disease. Clin Neurophysiol. 2002;113(2):243-53. https://doi.org/10.1016/S1388-2457(01)00723-4

28. Gironell A, Rodríguez-Fornells A, Kulisevsky J, Pascual B, Barbanoj M, Otermin P. Motor circuitry re-organization after pallidotomy in Parkinson disease: a neurophysiological study of the bereitschaftspotential, contingent negative variation, and N30. J Clin Neurophysiol. 2002;19(6):553-61. https://doi.org/10.1097/00004691-200212000-00009

29. Yamamoto J, Ikeda A, Satow T, Matsuhashi M, Baba K, Yamane F et al. Human eye fields in the frontal lobe as studied by epicortical recording of movement-related cortical potentials. Brain. 2004;127(4):873-87. https://doi.org/10.1093/brain/awh110

30. Singh J, Knight RT, Woods DL, Beckley DJ, Clayworth C. Lack of age effects on human brain potentials preceding voluntary movements. Neurosci Lett. 1990;119(1): 27-31. https://doi.org/10.1016/0304-3940(90)90747-W 